\title{
SANDIS IN DEFENCE OF FOUR SOCRATIC DOCTRINES John Shand
}

\author{
John Shand also critically discusses Sandis'preced- \\ ing paper.
}

While there is much that one may agree with in the paper, much of which gives a clear, fair and accurate view of the doctrines of Socrates and Plato, the nub of the criticism must rest on how much the plausibility of the overall thesis trades on the vagueness of the notion of recollection. The central thesis, which I hope I have understood, is that there are greater similarities between the philosophical methods and projects of Socrates and Wittgenstein than is often supposed, while usually their philosophies are regarded as quite opposite, if anything. What this similarity amounts to is that both philosophers see themselves as midwives to people who are perplexed by philosophical problems in that they are led to solutions to such problems by getting them to recall things they already know, albeit inchoately. Many philosophical problems arise from the attempt to understand certain basic features of the world. We may approach such an understanding by considering the concepts with which we think about such basic features - for example, truth, justice, knowledge, beauty. The supposed commonality in the methodology of Socrates and Wittgenstein arises from understanding the nature of these concepts by recalling how the words that denote them are actually used. Both gather up examples where the word denoting a concept is applied; that is to say their methodologies encourage us to recall how words are used.

But it may be argued that this is where the similarity ends. For their purposes in prompting this recollection are quite opposite. In the case of Socrates the aim is to show how the understanding of a concept cannot be acquired by recalling either how the words denoting the concepts are used, nor indeed by observing instances of things in the world to which it applies; the push then is to a different way of understanding concepts, that derived from the application of pure intellect, 
which will come up with a set of necessary and sufficient conditions capturing their essence. In the case of Wittgenstein the aim is to show that there is nothing more to understanding concepts than that which may be derived from recalling (being reminded of) the various ways in which we actually use the words which denote the concepts; from this we will be cured of our futile attempt to devise a set of timeless necessary and sufficient conditions that capture the supposed essence of concepts. Both these characterisations are crude, but true enough I think to show the radically different directions that Socrates and Wittgenstein are heading in.

Now it is true that Socrates does not come up with any set of necessary and sufficient conditions for the concepts he wishes to understand, nor does he accept the adequacy of any presented to him - but this does not mean they do not exist, and it is compatible with the view that we have simply not arrived at them yet. While in a sense it is rather puzzling and unsatisfactory that he never reaches final definitional solutions, his chief function is to show that such knowledge must be acquired through the intellect, and to reveal the false claims to knowledge and understanding he finds around him.

I have always taken it that Plato's use of the term 'recollection' is his way of making sense of a priori knowledge because he had no logical apparatus to handle it in any other way. In this he confuses nativism (innateness) with the a priori. True knowledge is necessary and unchanging, and because he thinks that knowledge must be knowledge of something, then there must be matching objects with the same qualities if there is knowledge at all. No such objects are presented to us by the senses, therefore such objects must exist in a sense-transcendent realm accessible by the only alternative to the senses, namely the intellect, which thus operates a priori. One somewhat misleading way of looking at this is to say that we would in cases of such a priori knowledge be accessing knowledge that we have before we turn to whatever is provided by the senses; so in a sense such knowledge involves recalling what we already know. Thus in proving Pythagoras' Theorem one does not have to consult any actual triangles - or if one 
did one would get a fuzzy, imprecise, ungeneralisable, and essentially untrue, result - but rather just think about triangles as such. But then the knowledge must already have "been in the mind'. Of course we now have a different, although still controversial, explanation as to how a priori knowledge is possible to do with notions such as analyticity, tautology, contradiction and logical form.

The upshot of this is to suggest that Plato's use of the idea of 'recollection' has two distinct meanings that should not be confused. The first is the everyday one of recalling how words like 'justice' are used. The second is a more technical usage, there to make sense of the idea that knowledge of concepts such as justice may be independent of sensory experience. Indeed the midwifery of the former kind of recollection is used as a means to give birth to the pursuit of the latter kind of recollection. In other words, recalling how words are actually used only goes to show its inadequacy as a method of providing knowledge and understanding of the concepts that the words denote, and that, therefore, for true knowledge and understanding of the concepts the words refer to, the other kind of recollection - intellectual thought alone - should be followed as the sound path to knowledge and understanding. I fear there is a conflation of these two notions of 'recollection' in the paper under comment here, one that makes it look plausible to suppose that when Wittgenstein talks of recollection or reminders, he is doing the same thing as Socrates. He is doing the same thing in the first sense of recollection, in a way, but his purpose is the opposite; Wittgenstein wishes through it to finish something not start something.

So, Wittgenstein would not countenance the Socratic picture of philosophical progress at all. Indeed his aim is to put paid to the temptation to move from the everyday sense of recollection - recalling, or reminding ourselves how words are actually used - to the conclusion that there must surely be more to be said, something pure and philosophical and timeless. But there can't be, because words get their meaning only in and through their use in a form of life, as otherwise they whir along in our understanding without actually changing or connecting 
to anything, although they may seem to do both, and therein lies our philosophical bamboozlement.

So, my conclusion is that l'd need a lot more convincing that the use of the notion of 'recollection' in Socrates-Plato and Wittgenstein gives good grounds for thinking that their projects and methodologies were interestingly similar, rather than as is usually thought, virtually opposite.

But perhaps all is not yet lost. One way out may be to draw a sharp distinction between Socrates and Plato. One might say that the former is Wittgensteinian in the sense that his project was to show that claims to knowledge were always flawed, and that our proper stance to the world should be the most modest form of belief. An eternally sceptical Socrates. When he says he doesn't have knowledge, we should take him seriously and do so because he thinks clearly no-one may have any. But that wasn't Plato's project. One might say on this basis that Plato uses Socrates' sceptical methods to show up certain claims to knowledge and methods of acquiring knowledge as fatally flawed in order to promote an alternative method that has nothing in common with any of the flawed methods and that will be successful. This of course involves applying to all knowledge the a priori methods so successful in mathematics and geometry. So, one might argue, whereas Wittgenstein has something in common with Socrates, he has less than nothing in common with Plato. It's impossible to see how this may be settled as we have no idea how to determine where Socrates ends and Plato begins; but I suspect, nevertheless, end in some way and begin in another way and in some fundamental manner they do.

However, even allowing for this we don't get to the point of really showing that Wittgenstein's methodology or project is like that of Socrates or Plato. For Wittgenstein is no sceptic - indeed his aim is to show how philosophical scepticism is itself based on the wrong way of looking at things - and the way that he does this is by reminding us how we actually go on - that if we look properly, in a way that takes seriously the way that our outlook is inextricably linked to our form of life, we will discover that everything is in order really - and this 
shows that he has no aim to take us 'beyond' to some exalted transcendent kind of knowledge or understanding (not in the cognitive, as opposed to spiritual, sense anyway). Wittgenstein was no sceptic, nor did he think that the meanings generated by recalling the ordinary usage of words should lead us to conclude that we need other methods to access eternal necessary transcendent philosophical truths concerning the things the words denote, as he did not he think there were such truths. These considerations taken together mean that Wittgenstein is no Socrates of any stripe and no Plato either, nor any combination of the two.

John Shand is Lecturer in Philosophy at The Open University. 